\title{
Morfogênese in vitro de variedades brasileiras de cana-de-açúcar
}

\author{
Daniela Anhel de Paula Cidade ${ }^{(1)}$, Renata de Oliveira Garcia( ${ }^{(1)}$, Aline Castellar Duarte(1), \\ Gilberto Sachetto-Martins ${ }^{(2)}$ e Elisabeth Mansur(1)
}

\begin{abstract}
(1)Universidade do Estado do Rio de Janeiro, Instituto de Biologia, Dep. de Biologia Celular e Genética, Rua São Francisco Xavier, no 524, Pavilhão Haroldo Lisboa da Cunha, CEP 20550-013 Rio de Janeiro, RJ. E-mail: daniela_cidade_6@hotmail.com, rogarcia@uerj.br, alinecastellar@ig.com.br, mansur@uerj.br (2)Universidade Federal do Rio de Janeiro, Centro de Ciências da Saúde, Instituto de Biologia, Dep. de Genética, Av. Brigadeiro Trompowsky, s/no-, CEP 21949-900 Rio de Janeiro, RJ. E-mail: sachetto@biologia.ufrj.br
\end{abstract}

\begin{abstract}
Resumo - O objetivo deste trabalho foi estabelecer sistemas de multiplicação de plantas de cana-de-açúcar in vitro e avaliar sua utilização, como material inicial, para a indução de regeneração a partir de ápices caulinares. Três métodos de cultivo foram avaliados: cultura em meio semi-sólido, cultura líquida estacionária e cultura líquida sob agitação. A taxa de multiplicação mais elevada foi alcançada por meio da cultura líquida sob agitação. Ápices caulinares, excisados dessas plantas, apresentaram taxas de regeneração in vitro compatíveis com sua utilização em protocolos de transformação. Calos resistentes a PPT e GUS-positivos foram obtidos de explantes da variedade Chunnee com inoculação de Agrobacterium tumefaciens C58C1 (pMP90) (pDUBarA9). O protocolo estabelecido a partir de cultivo in vitro pode ser utilizado para a produção de plantas transgênicas de cana-deaçúcar, visando à realização de estudos de regulação da expressão gênica, assim como à introdução de características de interesse agronômico.
\end{abstract}

Termos para indexação: Saccharum, micropropagação, transformação genética, Agrobacterium tumefaciens.

\section{In vitro morphogenesis of Brazilian sugarcane varieties}

\begin{abstract}
The objective of this work was to establish in vitro systems for sugarcane plant multiplication and for regeneration from shoot apices excised from these plants. Three methods were analyzed: culture on semi-solid medium and liquid culture with or without agitation. The highest regeneration rates were obtained from cultures in liquid-medium with agitation. Shoot tips derived from these plants presented regeneration rates suitable for utilization in transformation protocols. PPT-resistant and GUS positive calluses were obtained from explants of in vitro plants of Chunnee variety inoculated with Agrobacterium tumefaciens C58C1 (pMP90) (pDUBarA9). The established in vitro culture system can be applied for transgenic sugarcane production, aiming at gene regulation studies and introduction of agronomical traits.
\end{abstract}

Index terms: Saccharum, micropropagation, genetic transformation, Agrobacterium tumefaciens.

\section{Introdução}

A cana-de-açúcar é usada na produção de $65 \%$ do açúcar mundial, e também é matéria-prima para a produção de álcool, produtos farmacêuticos e outros compostos. Em decorrência da posição de destaque que ocupa na economia mundial, a cultura da cana está freqüentemente inserida em programas de melhoramento de espécies cultivadas, visando à introdução de características de interesse agronômico, como resistência a pragas e patógenos, tolerância a herbicidas, e aumento no teor de sacarose.

Em programas de melhoramento genético da canade-açúcar, há necessidade, sob determinadas circunstâncias, de se multiplicar o material selecionado com rapidez. A micropropagação é uma alternativa ao processo convencional de propagação vegetativa por meio de colmos. Altas taxas de multiplicação de cana-deaçúcar podem ser alcançadas por esse método, com inúmeras vantagens em relação à multiplicação em campo, como a produção de grande quantidade de mudas de qualidade superior, em tempo e espaço reduzidos (Malhotra, 1995). Protocolos eficientes para a regeneração in vitro são, também, fundamentais na utilização de técnicas de transformação genética, que oferecem novas possibilidades para a obtenção de variedades com características de interesse, além do melhoramento convencional.

Os protocolos já descritos para a regeneração in vitro de cana-de-açúcar têm como base processos de 
organogênese e embriogênese somática (Taylor \& Dukic, 1993; Falco et al., 1996). A produção de calos é obtida, geralmente, depois do cultivo de segmentos de folhas imaturas de plantas de campo, na presença de auxinas como 2,4-D (Gallo-Meagher et al., 2000) ou picloran (Fitch \& Moore, 1990). A regeneração a partir de calos ocorre em meio desprovido de reguladores de crescimento e na presença de luz (Taylor et al., 1992; Falco et al., 1996), podendo ser potencializada por diferentes hormônios vegetais (Chengalrayan \& GalloMeagher, 2001). Entretanto, como a resposta morfogênica é fortemente influenciada pelo genótipo, é fundamental que seja realizada adaptação dos protocolos em cada cultivar a ser utilizada.

Nos últimos anos, diferentes métodos de transformação genética de cana-de-açúcar foram desenvolvidos, contribuindo significativamente para a produção de novas variedades. Plantas resistentes a herbicida (Falco et al., 2000) e ao vírus-do-mosaico (Ingelbrecht et al., 1999) foram obtidas por bombardeamento de calos embriogênicos. Arencibia et al. (1997) produziram variedades resistentes a insetos, utilizando eletroporação de células intactas. Entretanto, problemas com relação aos métodos diretos de transformação já foram descritos, principalmente devido à baixa eficiência, formação de quimeras e freqüente integração de várias cópias do transgene ao genoma vegetal, desencadeando processos de silenciamento gênico (Bower et al., 1996).

A transformação genética via Agrobacterium tumefaciens apresenta vantagens em relação aos métodos diretos, resultando geralmente na integração de uma única cópia do transgene no genoma da planta. Além disso, a utilização desse sistema freqüentemente permite a obtenção de plantas a partir de uma única célula transformada (Riva et al., 1998). A transformação de cana-de-açúcar com a utilização de A. tumefaciens foi inicialmente descrita por Enríquez-Obregón et al. (1997). Plantas transgênicas resistentes à fosfinotricina, princípio ativo do herbicida comercial Basta, foram obtidas com o mesmo método, com a utilização de segmentos de folhas imaturas como tecidos-alvo (Enríquez-Obregón et al., 1998). No mesmo ano, foi também estabelecido um protocolo para a transformação de calos embriogênicos (Arencibia et al., 1998; Elliott et al., 1998). Mais recentemente, plantas resistentes ao mesmo herbicida foram obtidas, com o uso de gemas axilares (Manickavasagam et al., 2004).

O sucesso na obtenção de plantas transgênicas via A. tumefaciens é determinado por uma combinação de fatores, tais como o ajuste de condições de cultura de tecidos para cada variedade, visando ao aumento da competência das células para a incorporação do T-DNA e para a regeneração (Gallo-Meagher \& Irvine, 1993).

O objetivo deste trabalho foi estabelecer sistemas de multiplicação de plantas de cana-de-açúcar in vitro e avaliar sua utilização, como material inicial, para indução de regeneração a partir de ápices caulinares.

\section{Material e Métodos}

Foram utilizadas as variedades de cana-de-açúcar RB739735, RB758540, cedidas pela Pesagro, Campos, RJ, e Chunnee, cedida pelo Instituto de Ciências Biomédicas da Universidade Federal do Rio de Janeiro.

A desinfestação de segmentos de folhas imaturas de plantas da variedade RB739735 foi realizada de acordo com Chengalrayan \& Gallo-Meagher (2001). Para a indução de calos, os segmentos foram introduzidos em meio P5+Ao, composto por macronutrientes e micronutrientes do meio MS (Murashige \& Skoog, 1962), tiamina $1 \mathrm{mg} \mathrm{L}^{-1}$, piridoxina $0,5 \mathrm{mg} \mathrm{L}^{-1}$, ácido nicotínico $0,5 \mathrm{mg} \mathrm{L}^{-1}$, glicina $2 \mathrm{mg} \mathrm{L}^{-1} \mathrm{e}$ inositol $100 \mathrm{mg} \mathrm{L}^{-1}$, com $\mathrm{pH}$ 5,8. O meio foi suplementado com sacarose $20 \mathrm{~g} \mathrm{~L}^{-1}$, 2,4-D $5 \mathrm{mg} \mathrm{L}^{-1}$ e solidificado com ágar $8 \mathrm{~g} \mathrm{~L}^{-1}$. Depois da autoclavagem, foram adicionados ácido ascórbico $15 \mathrm{mg} \mathrm{L}^{-1}$, cisteína $40 \mathrm{mg} \mathrm{L}^{-1} \mathrm{e}$ nitrato de prata $2 \mathrm{mg} \mathrm{L}^{-1}$, esterilizados por filtração.

Os explantes foram incubados no escuro, a $28 \pm 2^{\circ} \mathrm{C}$, por 30 dias. Os calos foram subdivididos em fragmentos de, aproximadamente, $0,5 \mathrm{~cm}^{2}$ e subcultivados em $\mathrm{P} 5+$ Ao no escuro ou, alternativamente, em $\mathrm{P}+\mathrm{Ao}$ (P5+Ao sem a adição de 2,4-D), sob intensidade luminosa de $46 \mu \mathrm{mol} \mathrm{m}^{-2} \mathrm{~s}^{-1} \mathrm{e}$ fotoperíodo de 16:8 horas, para regeneração de brotos. As capacidades proliferativa e regenerativa de calos foram avaliadas mensalmente, durante seis meses.

Na avaliação da influência do método de cultivo sobre o potencial de multiplicação das plantas, brotos com aproximadamente $3 \mathrm{~cm}$ de altura, obtidos da regeneração de calos morfogênicos da variedade RB758540, foram cultivados em meio $\mathrm{P}+$ Ao solidificado ou líquido ( $\mathrm{LP}+\mathrm{Ao})$, em cultura estacionária ou sob agitação de $80 \mathrm{rpm}$. As culturas líquidas foram realizadas com grupos de dez brotos, em erlenmeyer de $300 \mathrm{~mL}$ de capacidade, com $5 \mathrm{~mL}$ ou $30 \mathrm{~mL}$ de meio, respectivamente. Depois de 30 dias, foram avaliados: o alongamento dos brotos, o diâmetro dos caules e a taxa de multiplicação (número de brotos produzidos a partir do broto inicial).

Na indução de calos, ápices caulinares, formados pelo meristema apical e dois a três primórdios foliares adjacentes (diâmetro de aproximadamente $1 \mathrm{~mm}$ ), foram 
excisados de plantas da variedade RB758540, obtidas em cultura líquida com agitação, e cultivados em meio P5+Ao, no escuro. Para induzir a regeneração direta de brotos, ápices caulinares foram cultivados em meio semisólido $\mathrm{P}+\mathrm{Ao}$, ou em LP+Ao, em cultura líquida estacionária ou sob agitação, nas condições descritas anteriormente. A altura dos brotos, o diâmetro dos caules e a taxa de multiplicação (número de brotos/explante) foram avaliados depois de 30 dias.

Os experimentos foram realizados com grupos de 40 explantes. Os resultados foram avaliados por análise de variância e pelo Tukey-Kramer Multiple Comparison Test, com a utilização do programa GraphPad InStat.

Nos experimentos de transformação genética, foi utilizada a cepa de A. tumefaciens C58C1pMP90 - cedida pelo Centro de Engenharia Genética e Biotecnologia de Havana, Cuba -, que contém o plasmídio pDUBarA9 como vetor binário. Esse plasmídio contém o gene repórter gusA-intron (Vancanneyt et al., 1990), fusionado ao promotor A9, construído a partir do promotor 35S, acrescido do primeiro exon e do primeiro intron do gene da actina 1 do arroz, e de quatro cópias da seqüência enhancer do gene da octopina sintase de Agrobacterium (González-Cabrera et al., 1998). O plasmídio também contém o gene bar, que confere resistência à fosfinotricina (PPT, princípio ativo do herbicida Basta), sob o controle do promotor UBI, isolado do gene da poli-ubiquitina 1 do milho (Christensen \& Quail, 1996).

As bactérias foram cultivadas em meio Yeast Extract Broth - YEB (Vervliet et al., 1975), suplementado com rifampicina $100 \mathrm{mg} \mathrm{L}^{-1}$, gentamicina $40 \mathrm{mg} \mathrm{L}^{-1} \mathrm{e}$ espectinomicina $100 \mathrm{mg} \mathrm{L}^{-1}$. A cultura foi incubada a $28 \pm 2^{\circ} \mathrm{C}$, sob agitação de $120 \mathrm{rpm}$, por aproximadamente 16 horas, até atingir $\mathrm{DO}_{620}=1,2$. A suspensão bacteriana foi diluída a 1:15, em meio sem os agentes seletivos, suplementado com acetosiringona $20 \mathrm{mg} \mathrm{L}^{-1}$, e incubada nas mesmas condições por, aproximadamente, 4 horas $\left(\mathrm{DO}_{620}=0,6\right)$.

Ápices caulinares excisados de plantas da variedade Chunnee, obtidas em cultura líquida com agitação, foram introduzidos em $10 \mathrm{~mL}$ de LP5+Ao, em grupos de dez explantes por frasco. Depois da adição de $1 \mathrm{~mL}$ da cultura bacteriana, os frascos foram agitados por 10 minutos, a $50 \mathrm{rpm}$, e mantidos em repouso por mais 10 minutos. Em seguida, os explantes foram transferidos para P5+Ao e novamente cultivados no escuro, por três dias. Depois desse período, os explantes foram transferidos para P5+Ao suplementado com cefotaxima $500 \mathrm{mg} \mathrm{L}^{-1}$, mantidos no escuro por cinco dias e transferidos para o meio P5+Ao suplementado com cefotaxima $500 \mathrm{mg} \mathrm{L}^{-1}$ e PPT $1 \mathrm{mg} \mathrm{L}^{-1}$. O material foi subcultivado a cada 15 dias, em meio seletivo de mesma composição. Os calos formados depois de 60 dias de cultivo foram submetidos ao ensaio enzimático da atividade de GUS, de acordo com Jefferson (1987).

\section{Resultados e Discussão}

Segmentos de folhas imaturas, excisados de plantas do campo da variedade RB739735 e cultivados em meio P5+Ao, originaram calos amarelados, nodulares e compactos, ou brancos e mucilaginosos (Figura 1). Os calos nodulares originaram brotos, depois da transferência para o meio P+Ao e cultivo na presença de luz. Ao contrário, os calos mucilaginosos não apresentaram formação de brotos nas mesmas condições. A adição de ácido $\alpha$-naftalenoacético (ANA) $1 \mathrm{mg} \mathrm{L}^{-1}+$ cinetina (KIN)

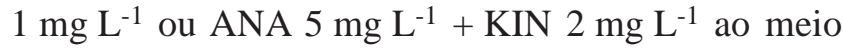
$\mathrm{P}+$ Ao não modificou esse comportamento. Uma correlação semelhante entre a morfologia dos calos de canade-açúcar e seu potencial morfogênico foi observada por outros autores (Taylor et al., 1992; Falco et al., 1996).

O estabelecimento de culturas de calos morfogênicos constitui uma alternativa para o suprimento de tecidosalvo, para obtenção de plantas transgênicas via A. tumefaciens (Arencibia et al., 1998; Elliot et al., 1998). Porém, a perda progressiva do potencial morfogênico dos calos, depois de sucessivos subcultivos, já foi descrita em diferentes variedades de cana-de-

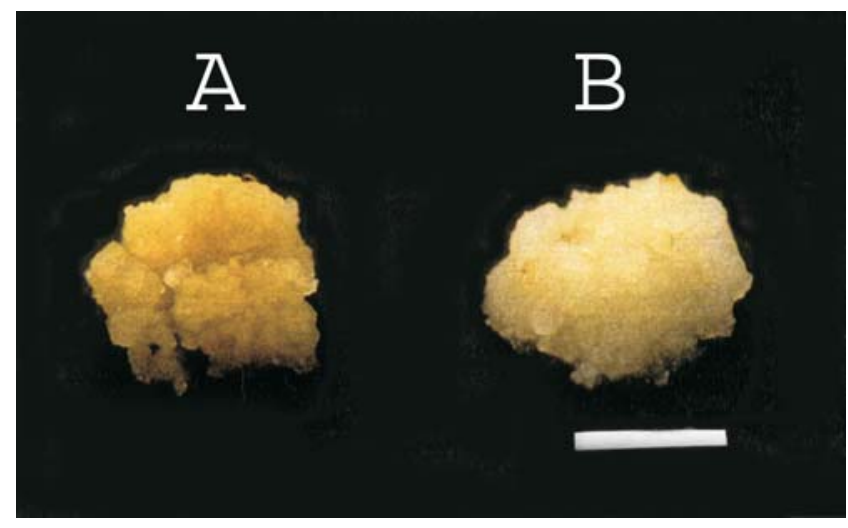

Figura 1. Proliferação de calos da variedade RB739735. A: calo nodular, compacto, morfogênico; B: calo branco, mucilaginoso, não morfogênico. Os calos foram obtidos a partir do cultivo de segmentos de folhas imaturas, excisados de plantas do campo em P5+Ao. Barra $=1 \mathrm{~cm}$. 
açúcar (Carrillo-Castañeda et al., 1986; Fitch \& Moore, 1990). A freqüência inicial de regeneração, obtida depois da transferência dos calos para o meio P+Ao e cultivo na presença de luz, foi de $94 \%$ (Figura 2). Depois do terceiro mês de cultivo, na presença de 2,4-D, houve perda significativa da capacidade regenerativa dos calos, que se acentuou aos cinco meses de subcultivo. Esses resultados restringem a utilização de calos da variedade RB739735 como tecidos-alvo para transformação genética aos três primeiros meses de subcultivo, de forma que a baixa eficiência de regeneração, observada depois desse período em cultura, não comprometa a obtenção de plantas a partir de células transformadas.

Em experimentos preliminares, a utilização de segmentos de folhas imaturas excisados de plantas do campo, em protocolos de transformação genética, não foi bem sucedida, provavelmente, em conseqüência de variações fisiológicas das plantas doadoras. Em decorrência dessas dificuldades, foram desenvolvidos sistemas de morfogênese, a partir de ápices caulinares de plantas in vitro, que tiveram como etapa inicial o estabelecimento de protocolos adequados à multiplicação de plantas doadoras. A Tabela 1 apresenta as taxas de

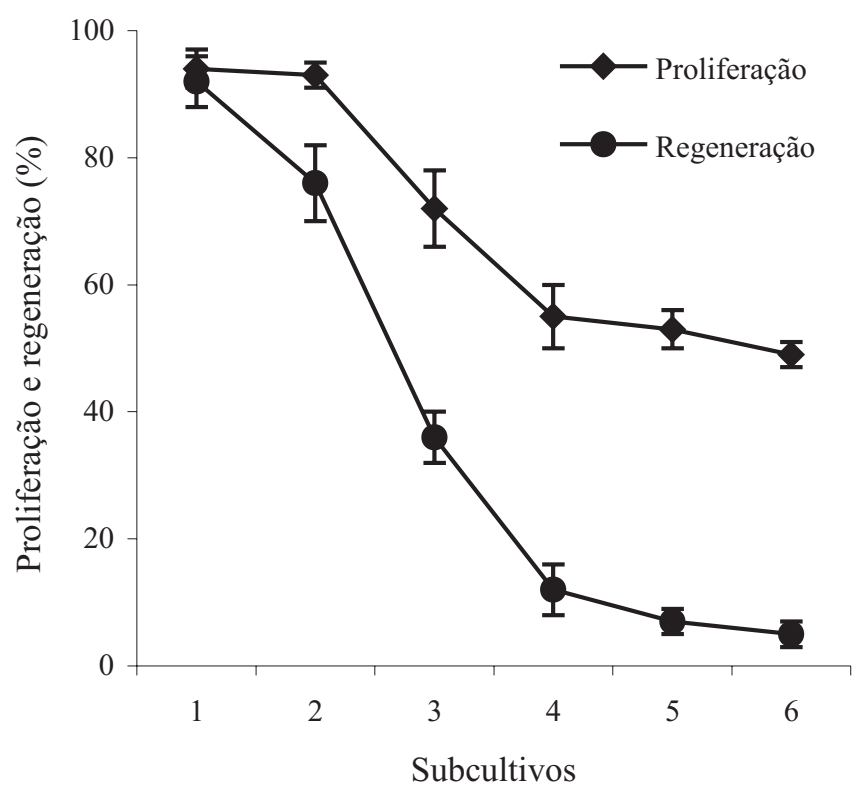

Figura 2. Capacidades proliferativa e regenerativa de calos da variedade RB739735, depois de sucessivos subcultivos. Os calos foram cultivados em P5+Ao, no escuro, para proliferação. Na obtenção de plantas, os calos foram transferidos para $\mathrm{P}+$ Ao e cultivados na presença de luz. proliferação de brotos da variedade RB758540, por perfilhamento, em três sistemas de cultura. A taxa de multiplicação de $12,1 \pm 0,4$, obtida por meio da cultura líquida com agitação, foi significativamente mais elevada $(p<0,05)$ do que as observadas em meio semi-sólido e em cultura líquida estacionária.

As plantas obtidas por meio da cultura líquida com agitação apresentaram altura e diâmetro do caule superiores, além de aspecto vigoroso (Figura 3), em oposição ao obtido em outros sistemas, com brotos mais curtos e diâmetro do caule inferior a $1 \mathrm{~mm}$. O cultivo de ápices caulinares excisados dessas plantas, em meio P5+Ao, no escuro, originou calos semelhantes aos obtidos a partir de segmentos de folhas imaturas de plantas do campo. Os ápices caulinares também foram cultivados nos três sistemas de cultura descritos anteriormente, tendo apresentado taxas de multiplicação semelhantes às contidas na Tabela 1 (Tabela 2). Esses resultados corroboram os de Taylor \& Durik (1993), que obtiveram baixos índices de multiplicação, depois do cultivo de ápices caulinares de diferentes variedades em meio semi-sólido, tendo sido necessária a utilização de fitorreguladores para a obtenção de regeneração eficiente. Lee (1986) também não alcançou resultados satisfatórios com o mesmo sistema, quando utilizou, alternativamente, a cultura líquida estacionária.

O sucesso do sistema de cultura líquida com agitação pode ser explicado, em parte, com base na incorporação de nutrientes e nas relações hídricas estabelecidas entre a planta e seu microambiente. Em meio semi-sólido, as trocas gasosas são favorecidas pela grande superfície em contato com o ar. Entretanto, a incorporação de nutrientes fica prejudicada, uma vez que só é realizada por meio da superfície basal da planta, que está em contato com o meio de cultura. Em cultura líquida estacionária, a incorporação de nutrientes é favorecida

Tabela 1. Avaliação do potencial de multiplicação de plantas, a partir de brotos da variedade RB758540(1).

\begin{tabular}{cccc}
\hline Método de cultivo & $\begin{array}{c}\text { Taxa de } \\
\text { multiplicação }\end{array}$ & $\begin{array}{c}\text { Altura dos } \\
\text { brotos }(\mathrm{cm})\end{array}$ & $\begin{array}{c}\text { Diâmetro do } \\
\text { caule }(\mathrm{mm})\end{array}$ \\
\hline $\begin{array}{c}\text { Cultura em meio } \\
\text { semi-sólido }\end{array}$ & $6,06 \pm 0,34 \mathrm{~b}$ & $8,86 \pm 0,35 \mathrm{~b}$ & $\leq 1 \mathrm{~b}$ \\
$\begin{array}{c}\text { Cultura líquida } \\
\text { estacionária }\end{array}$ & $4,30 \pm 0,25 \mathrm{c}$ & $7,03 \pm 0,28 \mathrm{c}$ & $\leq 1 \mathrm{~b}$ \\
$\begin{array}{c}\text { Cultura líquida } \\
\text { com agitação }\end{array}$ & $12,10 \pm 0,45 \mathrm{a}$ & $10,00 \pm 0,35 \mathrm{a}$ & $2,73 \pm 0,14 \mathrm{a}$ \\
\hline
\end{tabular}

(1)Os valores correspondem à média土erro-padrão; letras iguais, na coluna, indicam que não houve diferença significativa entre os tratamentos $(\mathrm{p}<0,05)$. 
pelo aumento de superfície vegetal em contato com o meio nutritivo, porém as trocas gasosas são prejudicadas (Lorenzo et al., 1998). No sistema de cultura líquida com agitação, além das facilidades de incorporação de nutrientes, as trocas gasosas são favorecidas pela constante aeração, provocada pela agitação do frasco de cultivo.

A manutenção in vitro de plantas doadoras de explantes apresenta vantagens para o estabelecimento de protocolos de cultura de tecidos e transformação genética. Na manutenção de estoques de material vegetal em médio prazo, a cultura em meio semi-sólido é uma alternativa eficaz, promovendo crescimento mais lento das plantas e requerendo um melhor número de subcultivos, que podem ser efetuados a intervalos de até três meses. Entre as vantagens desse sistema, encontram-se a redução de riscos, associados à
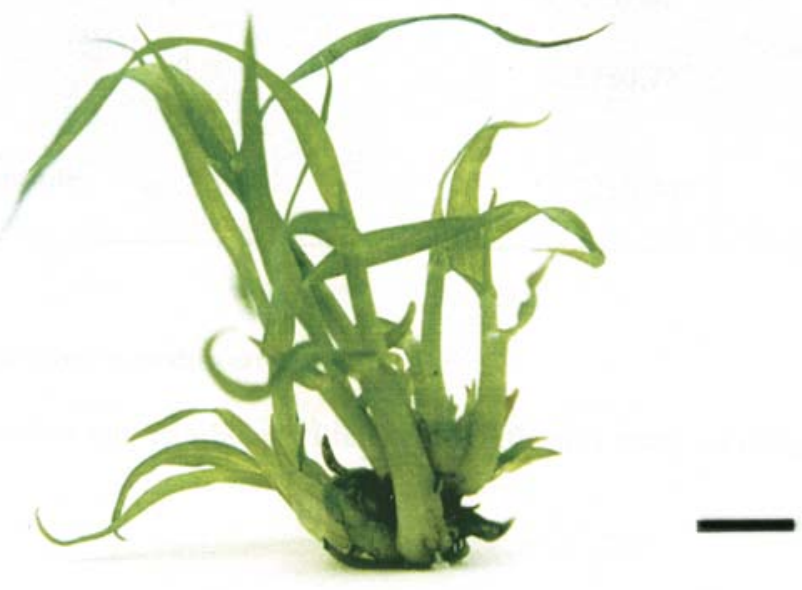

Figura 3. Planta da variedade RB758540, obtida por cultura líquida sob agitação. Broto isolado, com altura inicial de $1 \mathrm{~cm}$, cultivado por 30 dias em LP+Ao. Barra $=1 \mathrm{~cm}$.

Tabela 2. Avaliação do potencial de multiplicação de plantas, a partir de ápices caulinares da variedade RB758540(1) .

\begin{tabular}{cccc}
\hline Método de cultivo & $\begin{array}{c}\text { Taxa de } \\
\text { multiplicação }\end{array}$ & $\begin{array}{c}\text { Altura dos } \\
\text { brotos }(\mathrm{cm})\end{array}$ & $\begin{array}{c}\text { Diâmetro do } \\
\text { caule }(\mathrm{mm})\end{array}$ \\
\hline $\begin{array}{c}\text { Cultura em meio } \\
\text { semi-sólido }\end{array}$ & $5,03 \pm 0,21 \mathrm{~b}$ & $7,50 \pm 0,31 \mathrm{~b}$ & $\leq 1 \mathrm{~b}$ \\
$\begin{array}{c}\text { Cultura líquida } \\
\text { estacionária }\end{array}$ & $3,36 \pm 0,19 \mathrm{c}$ & $6,33 \pm 0,26 \mathrm{c}$ & $\leq 1 \mathrm{~b}$ \\
$\begin{array}{c}\text { Cultura líquida } \\
\text { com agitação }\end{array}$ & $10,90 \pm 0,30 \mathrm{a}$ & $9,96 \pm 0,34 \mathrm{a}$ & $2,66 \pm 0,13 \mathrm{a}$ \\
\hline
\end{tabular}

(1)Os valores correspondem à média土erro-padrão; letras iguais, na coluna, indicam que não houve diferença significativa entre os tratamentos $(\mathrm{p}<0,05)$. manipulação, e a economia de mão-de-obra e material de consumo. Por sua vez, a cultura líquida com agitação possibilita a produção de grande quantidade de plantas, em tempo reduzido, que podem ser empregadas diretamente em experimentos de cultura de tecidos e de transformação genética.

Nos dois sistemas, as plantas são obtidas a partir de gemas axilares, sem a formação de calos. A regeneração in vitro a partir de calos aumenta os riscos de variação somaclonal, o que constitui um problema, particularmente em cana-de-açúcar. Ao contrário, a regeneração a partir de gemas axilares apresenta riscos reduzidos para a estabilidade genética e é empregada na multiplicação de várias espécies (Manickavasagam et al., 2004).

Ápices caulinares excisados de plantas da variedade Chunnee, obtidas por cultura líquida com agitação, e cocultivados $\operatorname{com} A$. tumefaciens contendo o plasmídio pDUBarA9, originaram calos GUS-positivos (Figura 4), com uma freqüência de $5 \%$. O sucesso na transferência do material genético pode ter resultado de fatores genotípicos ou da alta eficiência dos promotores A9 (Enríquez-Obregón et al., 1998) e UBI (Gallo-Meagher \& Irvine, 1993) em cana-de-açúcar, além das condições fisiológicas favoráveis dos explantes, quanto à incorporação do T-DNA e à formação de calos.

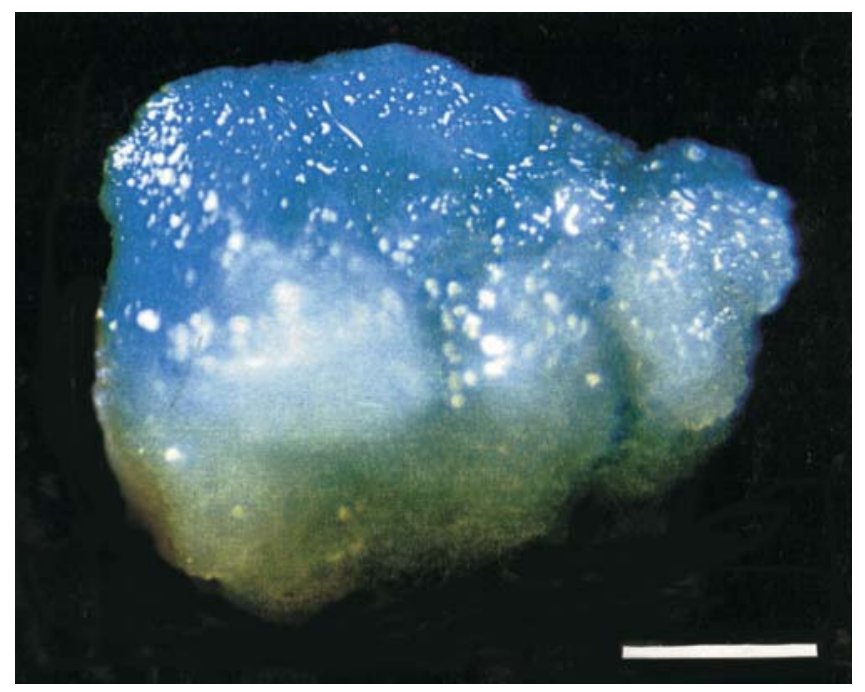

Figura 4. Expressão de GUS em calo da variedade Chunnee. O ápice caulinar foi excisado de planta obtida por cultura líquida sob agitação, submetido à inoculação de $A$. tumefaciens C58C1 (pMP90) (pDUBarA9) e mantido em meio P5+Ao suplementado com cefotaxima $500 \mathrm{mg} \mathrm{L}^{-1}$ e PPT $1 \mathrm{mg} \mathrm{L}^{-1}$ por 60 dias. Barra $=0,1 \mathrm{~cm}$. 
Os resultados deste trabalho demonstram que a utilização de explantes de plantas de cana-de-açúcar, em trabalhos experimentais de cultura de tecidos e de transformação genética, apresenta vantagens em relação ao material de campo, como a constante disponibilidade de material e a uniformidade fisiológica, em virtude do cultivo sob condições controladas. Além disso, a oxidação dos explantes é reduzida e não há necessidade de desinfestação do material vegetal, realizada com a utilização de procedimentos agressivos aos tecidos e potencialmente prejudiciais à regeneração in vitro.

\section{Conclusões}

1. O cultivo de brotos de cana-de-açúcar em meio líquido sob agitação possibilita aumento de $100 \%$ na produção de plantas, em comparação com o cultivo em meio semi-sólido.

2. Ápices caulinares excisados das plantas obtidas em meio líquido sob agitação apresentam regeneração eficiente, com a formação de calos morfogênicos ou a regeneração direta de brotos, com taxa de multiplicação elevada.

3. A manutenção de plantas in vitro proporciona constante disponibilidade de material uniforme e axênico, que pode ser utilizado em experimentos de cultura de tecidos e de transformação genética.

4. A obtenção de calos resistentes a PPT e GUS-positivos evidencia a aplicabilidade do sistema de cultivo in vitro na transformação de cana-de-açúcar via A. tumefaciens.

\section{Agradecimentos}

Ao CNPq, pelas bolsas concedidas; à Faperj, pelo suporte financeiro.

\section{Referências}

ARENCIBIA, A.D.; CARMONA, E.R.; TÉLLEZ, P.; CHAN, M.-T.; YU, S.M.; TRUJILLO, L.E.; ORAMAS, P. An efficient protocol for sugarcane (Saccharum spp. L.) transformation mediated by Agrobacterium tumefaciens. Transgenic Research, v.7, p.213222, 1998.

ARENCIBIA, A.D.; VÁZQUEZ, R.I.; PRIETO, D.; TÉLLEZ, P.; CARMONA, E.R.; COEGO, A.; HERNÁNDEZ, L.; RIVA, G.A. de la; SELMAN-HOUSSEIN, G. Transgenic sugarcane plants resistant to stem borer attack. Molecular Breeding, v.3, p.247255, 1997.

BOWER, R.; ELLIOT, A.R.; POTIER, B.A.M.; BIRCH, R.G. Highefficiency, microprojectile-mediated cotransformation of sugarcane using visible or selectable markers. Molecular Breeding, v.2, p.239249, 1996.

CARRILLO-CASTAÑEDA, G.; VARGAS, M.; VARGASVILLANUEVA, M. Cultivo in vitro de Saccharum officinarum L. II. Efecto de la especialización sobre la rediferenciación. Turrialba, v.36, p.533-540, 1986.

CHENGALRAYAN, K.; GALLO-MEAGHER, M. Effect of various growth regulators on shoot regeneration of sugarcane. In vitro Cellular and Development Biology - Plant, v.37, p.434-439, 2001.

CHRISTENSEN, A.H.; QUAIL, P.H. Ubiquitin promoter-based vectors for high-level expression of selectable and/or screenable marker genes in monocotyledonous plants. Transgenic Research, v.5, p.213-218, 1996.

ELLIOTT, A.R.; CAMPBELL, J.A.; BRETTELL, R.I.S.; GROF, C.P.L. Agrobacterium-mediated transformation of sugarcane using GFP as a screenable marker. Australian Journal of Plant Physiology, v.25, p.739-743, 1998.

ENRÍQUEZ-OBREGÓN, G.A.; VÁZQUEZ-PADRÓN, R.I.; PRIETO-SAMSÓNOV, D.L.; PEREZ, M.; SELMAN-HOUSSEIN, G. Genetic transformation of sugarcane by Agrobacterium tumefaciens using antioxidant compounds. Biotecnologia Aplicada, v.14, p.169174, 1997.

ENRÍQUEZ-OBREGÓN, G.A.; VÁZQUEZ-PADRÓN, R.I.; PRIETO-SAMSÓNOV, D.L.; RIVA, G.A. de la; SELMANHOUSEIN, G. Herbicide-resistant sugarcane (Saccharum officinarum L.) plants by Agrobacterium-mediated transformation. Planta, v.206, p.20-27, 1998.

FALCO, M.C.; MENDES, B.M.J.; TULMANN NETO, A.; GLORIA, B.A. da. Histological characterization of in vitro regeneration of Saccharum sp. Revista Brasileira de Fisiologia Vegetal, v.9, p.93-97, 1996.

FALCO, M.C.; TULMANN NETO, A.; ULIAN, E.C. Transformation and expression of a gene for herbicide-resistance in Brazilian sugarcane. Plant Cell Reports, v.19, p.1188-1194, 2000.

FITCH, M.M.M.; MOORE, P.H. Comparison of 2,4-D and picloram for selection of long-term totipotent green callus cultures of sugarcane. Plant Cell, Tissue and Organ Culture, v.20, p.157-163, 1990.

GALLO-MEAGHER, M.; ENGLISH, R.G.; ABOUZID, A. Thidiazuron stimulates shoot regeneration of sugarcane embryogenic callus. In vitro Cellular and Developmental Biology - Plant, v.36, p.37-40, 2000.

GALLO-MEAGHER, M.; IRVINE, J.E. Effects of tissue type and promoter strength on transient GUS expression in sugar-cane following particle bombardment. Plant Cell Reports, v.12, p.666670, 1993.

GONZÁLEZ-CABRERA，J.; COEGO-GONZÁLEZ, A.; MARTÍNEZ-GIL, A.F.; RIVA, G.A. de la; VÁZQUEZ-PADRÓN, R.I. Optimization of transgene expression in sugarcane cells. Biotechnology Techniques, v.12, p.793-796, 1998. 
INGELBRECHT, I.L.; IRVINE, J.E.; MIRKOV, T.E. Posttranscriptional gene silencing in transgenic sugarcane. Dissection of homology-dependent virus resistance in a monocot that has a complex polyploid genome. Plant Physiology, v.119, p.1187-1198, 1999.

JEFFERSON, R.A. Assaying chimeric genes in plants: the GUS gene fusion system. Plant Molecular Biology Reporter, v.5, p.387-405, 1987.

LEE, T.S.G. Multiplication of sugarcane by apex culture. Turrialba, v.36, p.231-236, 1986.

LORENZO, J.C.; GONZÁLEZ, B.L.; ESCALONA, M.; TEISSON, C.; ESPINOSA, P.; BORROTO, C. Sugarcane shoot formation in an improved temporary immersion system. Plant Cell, Tissue and Organ Culture, v.54, p.197-200, 1998.

MALHOTRA, S.D. Biotechnology and sugarcane. International Sugar Journal, v.97, p.160-163, 1995.

MANICKAVASAGAM, M.; GANAPATHI, A.; ANBAZHAGAN, V.R.; SUDHAKAR, B.; SELVARAJ, N.; VASUDEVAN, A.; KASTHURIRENGAN, S. Agrobacterium-mediated genetic transformation and development of herbicide-resistant sugarcane (Sacharum species hybrids) using axillary buds. Plant Cell Reports, v.23, p.134-144, 2004.
MURASHIGE, T.; SKOOG, F. A revised medium for rapid growth and bio assays with tobacco tissue cultures. Physiologia Plantarum, v.15, p.473-497, 1962.

RIVA, G.A. de la; GONZÁLEZ-CABRERA, J.; VÁZQUEZPADRÓN, R.; AYRA-PARDO, C. Agrobacterium tumefaciens: a natural tool for plant transformation. Electronic Journal of Biotechnology, v.1, p.24-25, 1998.

TAYLOR, P.W.J.; DUKIC, S. Development of an in vitro culture technique for conservation of Saccharum spp. hybrid germplasm. Plant Cell, Tissue and Organ Culture, v.34, p.217-222, 1993.

TAYLOR, P.W.J.; KO, H.L.; ADKINS, S.W.; RATHUS, C.; BIRCH, R.G. Establishment of embryogenic callus and high protoplast yielding suspension cultures of sugarcane (Saccharum spp. hybrids). Plant Cell, Tissue and Organ Culture, v.28, p.69-78, 1992.

VANCANNEYT, G.; SCHMIDT, R.; O’CONNOR-SANCHEZ, A.; WILLMITZER, L.; ROCHA-SOSA, M. Construction of an introncontaining marker gene: splicing of the intron in transgenic plants and its use in monitoring early events in Agrobacterium-mediated plant transformation. Molecular and General Genetics, v.220, p.245-250, 1990.

VERVLIET, G.; HOLSTERS, M.; TEUCHY, H.; VAN MONTAGU, M.; SCHELL, J. Characterization of different plaque-forming and defective temperate phages in Agrobacterium. Journal of General Virology, v.26, p.33-48, 1975.

Recebido em 2 de março de 2004 e aprovado em 8 de junho de 2005 